\title{
Neuro-Steroid Compound Found by GC-MS Analysis of The Methanolic Extract of The Leaves of Aegle marmelos (L) Corr.
}

\author{
Santi Ranjan Dey ${ }^{1}$, Subhasree Dutta ${ }^{2}$ and Mitu De $^{3^{*}}$ \\ ${ }^{1}$ Assistant Professor, Department of Zoology, Rammohan College, Kolkata, West Bengal, India \\ ${ }^{2}$ WBDST-JRF, Department of Zoology, Rammohan College, Kolkata, West Bengal, India \\ ${ }^{3}$ Associate Professor, Department of Botany, Gurudas College, Kolkata, West Bengal, India \\ Correspondence E-mail : mitude@rediffmail.com
}

\begin{abstract}
Aegle marmelos (L) Corr. has been widely used in indigenous systems of Indian medicine due to its various medicinal properties. All parts of this plant like fruit, leaves, bark, stem, roots are used as medicine from time immemorial in India. Recent research by several workers have shown that this plant possesses various significant activities such as antifungal, antioxidant, antibacterial, antiprotozoal, antispermatogenic, anti-inflammatory, anthelmintic, antidiabetic, laxative, febrifuge, and expectorant, chemopreventive, antipyretic, ulcer healing, antigenotoxic and diuretic. Despite the presence of these chemical compounds this plant remains as one of the underutilized fruits of West Bengal. The objective of this study was to determine if there was any novel bio-active compound in Bael with Gas Chromatography-Mass Spectrometry analysis method. As a result of our investigation using GC-MS analysis of the methanolic extract of the leaves of Aegle marmelos (L) Corr. the presence of a unique compound, a neuro-steroid, 3-hydroxy-pregnan-20-1 has been reported. It is a progesterone derivative. More research is needed to test the efficacy of this chemical compound, 3 hydroxy-pregnan-20-1 in vivo.
\end{abstract}

Keywords: Aegle marmelos (L) Corr., Bael. Ethono-medicine, Gas Chromatography-Mass Spectrometry, 3-hydroxy-pregnan-20-1

\section{Introduction}

Aegle marmelos (L) Corr. is a tree species native to the Indian subcontinent and Southeast Asia. It is also known as Bengal quince or stone apple. It is a perennial crop in India, Sri Lanka, Pakistan, Bangladesh, Myanmar, Thailand, Vietnam, the Philippines, Cambodia, Malaysia, Java, and other southeastern Asian countries (Roy and Sing. 1979). It is known as 'Bael' in Hindi, 'Bel' in Bengali, Oriya and Assamese; Vilvam in Tamil, bilavamu in Telugu and 'Bilwa' or 'Sriphal' in Sanskrit. Bael is considered as a sacred plant in India (Ariharan and Prasad.
2013). It is also known as 'Shivaduma' and is treated as a sacred tree by Hindus who associate it with Lord Shiva. The leaves are traditionally considered to be sacred and are used in rituals. Bael has trifoliate compound leaves. Each lobe is said to signify three functions of Lord Shiva, i.e. creation, preservation and destruction. They are also believed to represent three eyes of Lord Shiva. It is widely found in Indian Shiva temples.

Aegle marmelos (L.) Corr. is one of the important medicinal plants used to cure most 
of the common ailments of humans (Kumari et al, 2020). All the parts of this plant like fruit, leaves, bark, stem, roots are used in the treatment of different diseases (Baliga et al., 2011, Nirupama et al, 2012). Plants which are rich sources of ecologically developed secondary metabolites are often used as potent remedies for different ailments (Ganesh et al, 2011). This plant, Aegle marmelos (L.) Corr. is indigenous to India and has ethnomedical importance among the indigenous people of India (Dutta et al., 2014).

\section{Botanical description}

Aegle marmelos (L.) Corr. belongs to the family Rutaceae. Bael is a perennial tree, wild in the sub Himalaya tract, Central, and South India. Botanically, A. marmelos is a deciduous tree stretching up to $10 \mathrm{~m}$ in height that flower during the months of May-June. It is also commonly grown as a horticultural plant in India, and its fruits are processed as juice or candies, as well as eaten fresh

\section{Scientific classification}

Kingdom- Plantae

Division- Magnoliophyta

Class- Magnoliopsida

Order-Sapindales

Family- Rutaceae

Subfamily- Aurantioideae

Genus- Aegle Species- Aegle marmelos

Use of Aegle marmelos (L) Corr. in indigenous systems of Indian medicine

Aegle marmelos (L) Corr. has been widely used in indigenous systems of Indian medicine due to its various medicinal properties (Sahare et al 2008; Dhankhar and Ruhil, 2011). This plant has tremendous uses listed in Ayurvedic and Unani and Siddha Systems of medicine. Almost every part of this plant bears one or more of the medicinal properties utilized through preparation of different formulation either alone or in combination with other herbal plants (Malviya et al., 2012).

\section{Phyto-constituents of Aegle marmelos (L) Corr. \\ In recent years there has been considerable progress in the study the biological activities and medicinal applications of Bael plant. Extensive studies show that this plant possesses various significant activities such}

as antifungal, antioxidant, antibacterial, antiprotozoal, antispermatogenic, antiinflammatory, anthelmintic, antidiabetic, laxative, febrifuge, and expectorant, chemopreventive, antipyretic, ulcer healing, antigenotoxic, and diuretic (Kamalakkannan and Prince, 2003. Mukherjee et al., 2007; Raja et al., 2008, Lamia et al, 2018).

Aegle marmelos (L) Corr. has been reported to contain several phytoconstituents mainly marmenol, marmin, marmelosin, marmelide, psoralen, alloimperatorin, rutaretin, scopoletin, aegelin, marmelin, fagarine, anhydromarmelin, limonene, â-phellandrene, betulinic acid, marmesin, imperatorin, marmelosin, luvangentin and auroptene (Bansal and Bansal, 2011).

There are many active compounds which are chemically very active (Nirupama et al., 2012). A large number of biologically active compounds are found in the plant such as various organic acids including oxalic, tartaric, malic and ascorbic acid, various phenolics in the fruit as chlorogenic acid, ellagic acid, ferulic acid, gallic acid, protocatechuic acid and quercetin. In addition to these compounds like 1-Butanol, 3-methyl-, acetate, 1Dodecanol, 1- Heptadecanol(1-Eicosanol), 1Tetradecanol, acrylate; 1,3,4,5- Tetrahydroxy cyclohexane carboxylic acid (Quinic acid); 1,3Cyclohexadiene,2-methyl-5-(1-methylethyl)-(1Phellandrene); a-Cubebene; a-Tocopherol; allo imperatorin, Verbenone, vitamin $\mathrm{E}$ have been found in Aegle marmelos (L.) Corr. (Lamia et al, 2018).

Gas chromatography mass spectrometry (GC$M S)$

In the last few years, gas chromatography mass spectrometry (GC-MS) has become firmly established as a key technological platform for secondary metabolite profiling in both plant and non-plant species (Fernie et al., 2004, Robertson, 2005; Kell et al., 2005). GCMS is one of the best techniques to identify the constituents of volatile matter, long chain, branched chain hydrocarbons, alcohols acids, esters, etc. The identification of phytochemical compounds was based on the peak area, retention time and molecular formula. Phytochemical screening leaf extracts of $A$. marmelos has revealed the presence 
flavonoids, alkaloids, terpenoids, phenol and tanins saponins, steroids and coumarin (Sahu et al, 2019).

\section{Objectives}

Though Bael is a good source of bioactive components it is underutilized. So it is necessary to explore the bioactive components of bael which may be used in future for therapeutic purpose. This study tries to increase the medicinal value of bael by providing evidence-based in the form of information on the active compounds of the plant. The objective of this study was to determine if there was any new bio-active compound in Bael with Gas ChromatographyMass Spectrometry analysis method.

\section{Materials and Method}

\section{Collection of samples}

The leaves were collected from, Rammohan College, Kolkata, West Bengal campus. The collected leaves were cleaned and dried under shade. The powdered leaves were stored in the refrigerator for further use. Methanolic extract were prepared from the powdered leaf.

\section{GC-MS}

The experiment was carried out in the Central Instrumentation Facility, Bose Institute, Kolkata, India. For GC-MS Thermofisher GC was used. The column (HP5) was fused silica $50 \mathrm{~m} \times 0.25 \mathrm{~mm}$ I.D. Analysis conditions were 20 minutes at $100^{\circ} \mathrm{C}, 3$ minutes at $235^{\circ} \mathrm{C}$ for column temperature, $240^{\circ} \mathrm{C}$ for injector temperature, helium was the carrier gas and split ratio was $5: 4$. The sample $(1 \mu \mathrm{l})$ was evaporated in a split less injector at $300^{\circ} \mathrm{C}$. Run time was 22 minutes. The components were identified by GC coupled with MS.

\section{Identification of components}

Interpretation of the mass spectrum, GC-MS was conducted using the database of National Institute Standard and Technology (NIST) having more than 62,000 patterns. The spectrum of the unknown components was compared with the spectrum of the known components stored in the NIST library. The name, molecular weight and structure of the components of the test materials were ascertained.

\section{Result}

The identification of phytochemical compounds was based on the peak area, retention time and molecular formula (Fig.1, Table 1 and Table 2)

The compound was identified 3-hydroxypregnan-20-1. This compound is reported for the first time from Aegle marmelos (L) Corr. Pregnanolone has sedative, anxiolytic, anesthetic, and anticonvulsant effects. (Reddy, 2003) During pregnancy, pregnanolone and allopregnanolone are involved in sedation and anesthesia of the fetus. ((Lagercrantz and Changeux. 2009). The compound is potentially used against anxiety disorder, seizure and depression disorder.

Table 1: The compound identified 3-hydroxy-pregnan-20-1. Following details were observed from https://pubchem.ncbi.nlm.nih.gov/compound:

\begin{tabular}{|c|c|c|c|}
\hline Structure & $\begin{array}{l}\text { Molecular } \\
\text { Formula }\end{array}$ & $\begin{array}{l}\text { Molecular } \\
\text { Weight }\end{array}$ & Synonyms \\
\hline & $\underline{\mathrm{C}_{21}} \underline{\mathrm{H}_{34}} \underline{\mathrm{O}}_{2}$ & $318.5 \mathrm{~g} / \mathrm{mol}$ & $\begin{array}{l}\text { Allopregnanolone } \\
\text { CAS 516-55-2 } \\
\text { MLS001335972 } \\
\text { 3.beta.-Hydroxy-5.alpha.-pregnan-20-one } \\
\text { 1-(3-hydroxy-10,13-dimethyl- } \\
\text { 2,3,4,5,6,7,8,9,11,12,14,15,16,17- } \\
\text { tetradecahydro-1H- } \\
\text { cyclopenta[alphenanthren-17-vl) ethanone }\end{array}$ \\
\hline
\end{tabular}


Int J Adv Life Sci Res. Volume 3(4)51-56

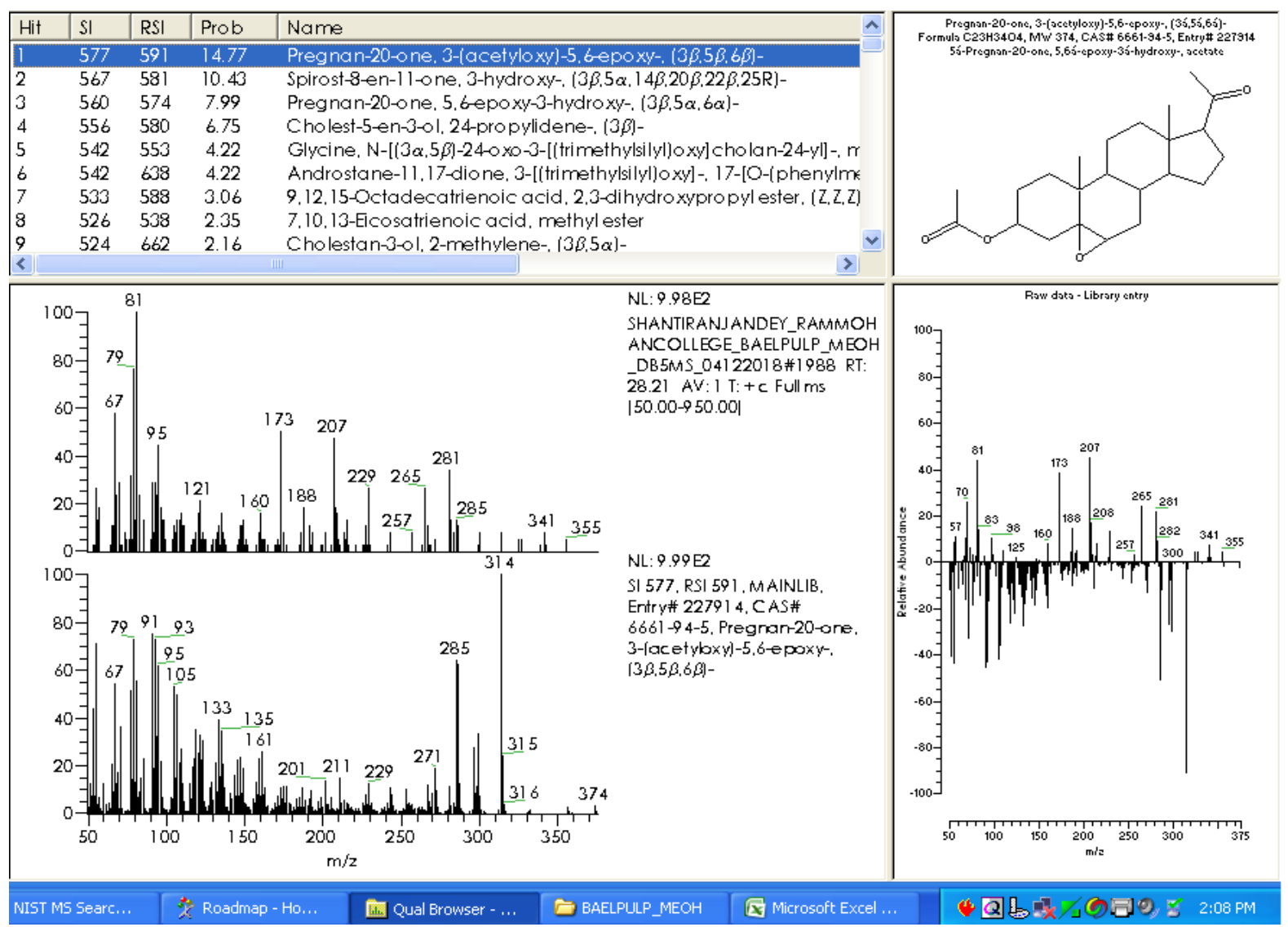

Figure 1. GC MS spectra and NIST result for identification of compound.

Table 2 : Physical and Chemical properties of the compound, 3-hydroxy-pregnan-20-1. (Source:

https://pubchem.ncbi.nlm.nih.gov/compound)

\begin{tabular}{|l|l|}
\hline Property Name & Property \\
\hline Molecular Weight & 318.5 \\
\hline XLogP3-AA & 4.9 \\
\hline Hydrogen Bond Donor Count & 1 \\
\hline Hydrogen Bond Acceptor & 2 \\
\hline Rotatable Bond Count & 1 \\
\hline Exact Mass & 318.25588 \\
\hline Monoisotopic Mass Surface & 318.25588 \\
\hline Topological Polar & 37.3 \\
\hline Heavy Atom Count & 23 \\
\hline Formal Charge & 0 \\
\hline Complexity & 500 \\
\hline Isotope Atom Count & 0 \\
\hline $\begin{array}{l}\text { Defined Atom Stereocenter } \\
\text { Count }\end{array}$ & 0 \\
\hline $\begin{array}{l}\text { Undefined Atom Stereocenter } \\
\text { Count }\end{array}$ & 8 \\
\hline
\end{tabular}

\section{Discussion}

Aegle marmelos (L) Corr. or Bael is reported to contain several phytochemicals, coumarins, alkaloids, sterols and essential oils showing antimicrobial, antidiabetic, antiinflammatory, analgesic, antipyretic, hypoglycaemic, wound healing, insecticidal properties (Lambole et al, 2010). A. marmelos leaf, seed and fruit is known to affect male fertility in reversible manner. A. marmelos bark extract is a rich source of marmin and fagarine known for reducing male fertility. Antifertility properties have been reported by several workers viz. (Chauhan and Agarwal. 2008; Agrawal et al., 2012, De et al., 2015). There are many reports available on the medicinal and industrial values of Aegle marmelos (L) Corr. or Bael in India (Kamalakkannan and Prince, 2003. Mukherjee et al., 2007; Raja et al., 2008, Sahu et al, 2019).

\section{Conclusion}

As a result of our investigation using GC-MS analysis of the methanolic extract of the leaves of Aegle marmelos ( $L$ ) Corr. the presence of a 
unique compound, a novel neuro-steroid, 3hydroxy-pregnan-20-1 has been reported. It is a progesterone derivative. Neuro-active steroids have been claimed to have specific physiological roles in normal or pathological brain function (Mellor et al., 2005). This compound, 3-hydroxy-pregnan-20-1 from $A$. marmelos (L.) Corr. may be useful in the future medicine development. More research is needed to test the efficacy of this chemical compound, 3-hydroxy-pregnan-20-1 in vivo.

\section{Acknowledgments:}

The authors would like to thank Prof Sujoy Dasgupta of Bose Institute and Mr. Smriti

\section{References}

Agrawal S.S., Kumar A., Gullaiya S., Dubey V., Nagar A., Tiwari P., et al. 2012. Antifertility activity of methanolic bark extract of Aegle marmelos (L.) in male wistar rats. Daru; 20(1): 94.

Ariharan VN, Prasad PN. 2013. 'Mahavilva' A sacred tree with immense medicinal secrets. A mini review. Rasayan J Chem; 6(4): 342-52.

Baliga MS, Bhat HP, Joseph N, Fazal F. 2011. Phytochemistry and medicinal uses of the bael fruit (Aegle marmelos (L.) Correa): A concise review. Food Res Int.; 44: 1768-1775.

Bansal $Y$ and Bansal G. 2011. Analytical methods for standardization of Aegle marmelos: A review. J Pharm Educ Res.; 2(2): 37-44.

Chauhan A, Agarwal M. 2008. Reversible changes in the antifertility induced by Aegle marmelos in male albino rats. Syst Biol Reprod Med.; 54(6): 240-246.

De, Mitu, Chowdhury, Rita, Chattoraj, Sounima, Dutta, Upasana, Tripathy, Smritiratan Pal, Ankush and Dey, Santi Ranjan. 2015. Studies on Antifertility Activity of Bark Aqueous Extracts of Aegle marmelos (L.) Corr. in male Bandicota bengalensis (Gray, 1835): In search for a potential Rodenticide. Indian Journal of Biology (ISSN 2394- 1391) IJB, Vol.2 No.2 Jul-Dec 2015, pp. 135- 139.

Dhankhar S and Ruhil S. 2011. Aegle marmelos (Linn): a potential source of phytomedicine. J Med Plant Res; 5(9): 1497-1507.

Dutta A, Lal N, Naaz M, Ghosh A, Verma R. 2014. Ethnological and Ethno-medicinal importance of Aegle marmelos (L.) Corr (Bael) among indigenous people of India. AJEthno.; 1: 290-312.

Fernie AR, Trethewey RN, Krotzky AJ, Willmitzer L. 2004. Metabolite profiling: From diagnostics to systems biology. Nat Rev Mol Cell Biol.; 5: 763-9.
Kumar Majhi, Central Instrument Facility, Bose Institute, Kolkata, India for their support and assistance to carry on the GC-MS analysis. The authors also thank the Principal, Rammohan College, Kolkata, India and the Principal, Gurudas College, Kolkata, India for providing support to carry on this work.

\section{Conflicts of Interest:}

The authors declare that there are no conflicts of interest regarding the publication of this work.

Ganesh N S, Susheel K D, Piush S and Nitin S. Medicinal values of bael (Aegle marmelos) (L.) Corr.: a review. Inr J Cur Phar Rev Res , 2011; 1 : 12-22.

Kamalakkannan N and Prince P.S. 2003. Hypoglycaemic effect of water extracts of Aegle marmelos fruits in streptozotocin diabetic rats. $\mathrm{J}$ Ethnopharmacol.; 87: 207-210.

Kell DB, Brown M, Davey HM, Dunn WB, Spasic I, Oliver SG. 2005. Metabolic footprinting and systems biology: The medium is the message. Nat Rev Microbiol.; 3: 557-65.

Kumari Anupama, Tiwari R. C, Sharma Ved Bhushan and Tiwari, Shashikant. 2020. Bilwa (Aegle marmelos) - A Review Article. International Ayurvedic Medical Journal, Vol. 8 (2), Feb, 2792 2796.

Lagercrantz H, Changeux J.P. 2009. The emergence of human consciousness: from fetal to neonatal life. Pediatr. Res. 65 (3): 255-60.

Lambole, Vijay B., Murti, Krishna, Kumar, Upendra, Bhatt, Sandipkumar, P. and Gajera. Vipul. 2010. Phytopharmacological properties of Aegle Marmelos as a potential medicinal tree: An overview. International Journal of Pharmaceutical Sciences Review and Research. Vol. 5.(2), pp.67 72.

Lamia, Samanta Sifat, Shimo, Mafia Sultana, Rashed, Sadman Sakib Bin, Prima, Afroza Afrin, Mony, Armin Tania and Dash, Pritesh Ranjan. 2018. Phytochemistry and Pharmacological Properties of Aegle marmelos L (Rutaceae): A Review. International Journal of Research in Pharmacy and Pharmaceutical Sciences Vol. 3 (3); 45-54 pp.

Malviya Rishabha , Kumar Ajay, Singh Anupama, Kulkarni GT . 2012. Pharmacological Screening, 
Int J Adv Life Sci Res. Volume 3(4)51-56

Ayurvedic values and Commercial Utility of Aegle Marmelos, Int. J. Drug Dev. \& Res., Jan-March 2012, 4(1): 28-37.

Mellor D.J., Diesch T. J., Gunn A.J., Bennet L. 2005. The importance of 'awareness' for understanding fetal pain. Brain Res. Brain Res. Rev. 49 (3): 455- 71.

Mukherjee P. K., Rai S, Kumar V., Mukherjee K., Hylands P. J., Hider R. C. 2007. Plants of Indian origin for drug discovery. Expert Opin Drug Discov; 2: 633-657.

Nirupama G.S., Padmasri G., Ramesh R.V., Vasanthi M. 2012. Comparative analysis of phytochemical constituents present in various parts of Aegle marmelos. Asian Pac J Trop Dis.; 2:774777.

Raja S. B, Murali M.R, Devaraj S. N. 2008. Differential expression of ompC and ompF in multidrug-resistant Shigella

dysenteriae and Shigella flexneri by aqueous extract of Aegle marmelos, altering its susceptibility toward $\beta$-lactam antibiotics. Diagn Microbiol Infect Dis.; 61:321-328.
Reddy D S. 2003. Pharmacology of endogenous neuroactive steroids. Crit Rev. Neurobiol. 15 (3-4): 197-234.

Robertson DG. 2005. Metabonomics in toxicology: A review. Toxicol Sci.; 85: 809-22.

Roy S. K, Sing R. N. 1979. Bael fruit (Aegle marmelos): A potential fruit for processing. Econ Bot.; 33: 203-212.

Sahare K. N., Anandhraman V., Meshram V. G., Meshram S. U., Reddy M. V., Tumane P. M. and Goswami K. 2008. Anti- microfilarial activity of methanolic extract of Vitex negundo and Aegle marmelos and their phytochemical analysis. Indian J. Exp. Biol. 2008; 46(2): 128-31.

Sahu AK, Kar BR, Deepthi K, Pallath KS, Dakni SJ, Samal P, Niharika NS, Swetha T, Sneha T, A. Anthony SP and HG Varshini R. 2019. Gas chromatography and mass spectroscopy analysis and phytochemical characterization of Aegle marmelos (Bael) leaf, Stem and its screening of antimicrobial activity. GSC Biological and Pharmaceutical Sciences, 8(3), 122-130. 